\title{
Estudo da viabilidade do uso de resíduos líquidos no cultivo da microalga Chlorella sp visando a produção de biocombustíveis
}

\author{
Feasibility study of the use of liquid waste in the cultivation of microalgae Chlorella sp aimed at producing biofuels
}

\author{
Tamires de Queiroz Vieira', Weruska Brasileiro Ferreira², Hélvia Waleska Casullo de Araújo ${ }^{3}$, Tássio Henri- \\ que Cavalcanti da Silva Cunha ${ }^{4}$, lana Chaiene de Araujo Vidal ${ }^{5}$, Débora Jamila Nóbrega de Melo \\ 'Pós-graduanda, Departamento de Engenharia Sanitária e Ambiental, Universidade Federal da Paraíba, Campina Grande, Brasil \\ 2Doutora em Engenharia Química, Universidade Estadual da Paraíba, Campina Grande, Brasil. \\ ${ }^{3}$ Doutora em Biotecnologia em Recursos Naturais, Universidade Estadual da Paraíba, Campina Grande, Brasil. \\ ${ }^{4,5}$ Acadêmicos de Engenharia Sanitária e Ambiental, Campina Grande, Brasil. \\ ${ }^{6}$ Mestranda em Engenharia Química, Campina Grande, Brasil.
}

\section{Resumo}

\begin{abstract}
O mundo vive uma dupla crise mundial devido ao uso excessivo de combustíveis fósseis e seus efeitos danosos ao meio ambiente. Logo, é imprescindível obter fontes energéticas renováveis. Assim, surgem às microalgas como uma opção atrativa para geração de energias renováveis, pois algumas espécies contêm lipídios e carboidratos que podem ser extraídos para produção de biocombustíveis. As microalgas também contribuem com a redução do lançamento inadequado das águas residuarias, pois podem ser desenvolvidas em meios de cultivo contendo águas residuarias, reduzindo o efeito poluidor dos resíduos líquidos. Este trabalho estudou o crescimento celular da microalga Chlorella sp em cultivos mixotróficos, através da adição de águas residuárias a meio de cultura Bold's Basal Medium. Primeiramente utilizou glicerina ao meio de cultura em diferentes proporções ( $2 \%, 4 \%$ e 10\%), os resultados alcançados não foram satisfatórios para o desenvolvimento da microalga em estudo, inviabilizando o uso da glicerina para o cultivo de Chlorella sp. A segunda etapa consistiu na suplementação da vinhaça ao meio em diferentes teores (10\%, $15 \%, 20 \%$ e $25 \%$ ), os resultados obtidos foram satisfatórios, pois, a vinhaça apresentava características nutritivas para o crescimento das microalgas. A proporção de vinhaça que obteve melhor crescimento foi com a suplementação de $10 \%$, onde verificou excelente adaptação das células a nova composição do meio de cultivo. Com adição de vinhaça em concentrações maiores que $10 \%$ ao meio, observou uma maior dificuldade no crescimento celular, devido ao excesso de material suspenso presente na vinhaça favorecendo o arraste das microalgas. Logo, com os resultados obtidos com o uso da vinhaça concluiu-se que o seu uso é viável para o cultivo da Chlorella sp, além de favorecer um destino adequado para o resíduo líquido das indústrias sucroalcooleiras, promove também o desenvolvimento de microalgas, possibilitando a geração de novas fontes sustentáveis de energias renováveis.
\end{abstract}

Palavras-chaves: Biocombustíveis; Microalga; Vinhaça; Glicerina.

\begin{abstract}
The world is experiencing a global double crisis due to excessive use of fossil fuels and their harmful effects on the environment. Therefore, it is essential to obtain renewable energy sources. Thus arise the microalgae as an attractive option for renewable energy generation, as some species of microalgae contain lipids and carbohydrates that can be extracted for biofuel production. Microalgae also contribute to reducing the inappropriate release of wastewater, because they can be grown in culture media containing wastewater, reducing the pollution effect of the liquid waste. This work studied the cell growth of microalgae Chlorella sp in mixotróficos crops, through the addition of wastewater to the culture medium Bold's Basal Medium. First glycerin used to culture medium in different ratios $(2 \%, 4 \%$ and $10 \%)$, the results were not satisfactory for the development of microalgae studied, making it impossible to use glycerin for the cultivation of Chlorella sp. The second step consisted of supplementation of vinasse to the medium at different concentrations $(10 \%, 15 \%, 20 \%$ and $25 \%)$, the results were satisfactory, since the slop had nutritional characteristics for the growth of microalgae. The proportion of vinasse that better growth was obtained with supplementation of $10 \%$ where found excellent adaptation of the cells to the new composition of the culture medium. With vinasse at levels greater than $10 \%$ in half, noted greater difficulty in cell growth due to excessive suspended material present in the vinasse favoring the drag of microalgae. Therefore, the results obtained from the use of vinasse concluded that its use is feasible for the cultivation of Chlorella sp, besides favoring a suitable destination for the liquid residue of sugarcane industries, also promotes the development of microalgae, enabling generation of new sustainable sources of renewable energy.
\end{abstract}

Keywords: Biofuels; Microalgae; Vinasse; Glycerin. 


\section{INTRODUÇÃO}

O mundo com o uso excessivo dos combustíveis fósseis pelas indústrias e principalmente pelo setor de transporte faz com que se viva uma dupla crise mundial que é a escassez das fontes de combustíveis fósseis e a degradação ambiental.

Desta forma, seja pelos efeitos negativos causados ao meio ambiente ou esgotamento das reservas de combustíveis fósseis, é imprescindível e urgente à procura de fontes energéticas alternativas renováveis, biodegradáveis, de produção limpa e não tóxicas e que sejam de custo competitivo com as atuais fontes de energia existente. Dentro desse prisma, destacam-se os biocombustíveis, como fontes de energia renováveis e biodegradáveis, onde possuem inúmeras vantagens ambientais, como a redução das emissões de poluentes, principalmente os gases de efeito estufa responsáveis pelo superaquecimento global.

Atualmente o país que vem se destacando mundialmente na produção de energia limpa e renovável é o Brasil que possui em sua matriz energética $45 \%$ de energia renovável, enquanto no mundo este valor não ultrapassa a 14\% (EMBRAPA, 2010).

É importante ressaltar que, os estados de Alagoas, Pernambuco e Paraíba representam $73 \%$ da produção de etanol da região Norte - Nordeste, sendo o estado da Paraíba o segundo maior produtor do Nordeste, que representa $24 \%$ do PIB anual da agricultura do Estado. No entanto, existe uma limitação de crescimento no setor dentro do estado da Paraíba em razão da área física não permitir uma extensão em virtude dos seguintes fatores: dificuldade topográfica, clima, períodos prolongados de seca e baixa fertilidade do solo (PAIXÃO e FONSECA, 2011).

O biocombustível que vem se destacando no cenário mundial atualmente é representado em sua maioria pelos derivados de culturas terrestres, tais como: soja, milho, cana-de-açúcar. No entanto, vem a cada dia sendo pressionado pelo mercado de alimentos devido à enorme área de terras agricultáveis necessárias para sua produção, além de contribuir também com a escassez de água potável e para a destruição das florestas no mundo.

No entanto, dentro da realidade e da necessidade que o mundo vive em obter uma fonte de energia renovável, as microalgas surgem atualmente, como à única matéria-prima sustentável capaz de assegurar a produção de biocombustíveis de acordo com Chisti (2007).

A produção de biocombustíveis a partir de microalgas terá um menor impacto ambiental, não competindo por espaço com as culturas alimentares ao contrário dos biocombustíveis produzidos a partir de outras matérias primas (MIRANDA, 2011), além de dar um destino adequado para as águas residuais.

Microalgas podem oferecer vários tipos de biocombustíveis renováveis. Estes incluem o metano ou biogás produzido pela digestão anaeróbica da biomassa, o biodiesel derivado dos lipídios das microalgas, biohidrogênio produzido pela lignina celulósica por meio da fermentação, bioetanol e biobutanol obtido do açúcar da biomassa por meio de fermentação (BOROWITZKA, 1999; MALCATA, 2011). A microalga Chlorella sp tem uma imensa importância econômica, não só na produção para aplicação na alimentação humana. Mas, também na geração de bioenergia, tornando-se uma alternativa como fonte de energia renovável (PHUKAN et al., 2011).

A microalga Chlorella vulgaris, particularmente, tem apresentado potencial como matéria-prima para produção de bioetanol devido a seu elevado acúmulo celular de amido em peso seco em torno de 37\% (VAN HANH et al., 2012).

O cultivo autotrófico é o mais utilizado no cultivo de microalgas, principalmente quando a produção é em larga escala. Mas, várias espécies podem tanto ser cultivadas em processos autotróficos, heterotróficos e mixotróficos.

O desenvolvimento de meios de cultura com base em águas residuais tem-se uma área importante do estudo, o que resulta em um grande número de meios de cultura obtidos a partir de diferentes tipos de suportes minerais, substratos orgânicos, sintéticos e de águas residuais (ORPEZ et al., 2009; DICKNSON et al., 2013; TUANTET et al., 2013).

Uma das fontes de carbono mais adequada para produção de biodiesel por meio mixotrófico é o glicerol, esse pode ser obtido como subproduto da reação de transesterificação para obtenção do biodiesel. O acúmulo de lipídios é maior quando utiliza o glicerol que as outras fontes de carbono como a glicose por exemplo.

Em várias unidades sucroalcooleiras, a vinhaça está sendo largamente utilizada como fertilizante. 
No entanto, esse uso, não deve ser indiscriminado, pois pode impactar o meio ambiente, causando efeitos como a salinização do solo e a poluição de aquíferos (PRADO, 2007).

Assim sendo, com o intuito de avaliar a potencialidade da produção de biocombustível através das microalgas, este trabalho estudou a otimização do cultivo da microalga Chlorella sp juntamente com o uso de águas residuárias, dando assim um uso adequado dos rejeitos e evitando assim possíveis processos de contaminação do solo e dos corpos d'águas, bem como fornecer uma nova fonte de geração de biocombustíveis líquidos incrementando a geração de energia nas indústrias de biocombustíveis de primeira geração e segunda geração, em especial na região Nordeste que já possui sua matriz industrial consolidada na produção de etanol, com a forte opção de tornar as indústrias sucroalcooleira uma unidade de biorrefinaria devido ao processamento de várias biomassas na geração de energia com possibilidades de alcançar as metas de produção e consumo de biocombustíveis, em função das limitações das fontes atualmente empregadas para geração de etanol de primeira geração.

\section{METODOLOGIA}

\subsection{Microalga}

Para este estudo foi utilizado cepas da espécie da microalga Chlorella sp existentes no Laboratório de Saneamento da Universidade Estadual da Paraíba, que foram fornecidas pelo Laboratório de Biotecnologia Alimentar da Universidade Federal de Santa Catarina e pelo Laboratório de Biologia Marinha da Universidade Federal Fluminense.

\subsection{Preparação do material de cultivo}

Todo o material utilizado para o cultivo da Chlorella sp passou por um rigoroso processo de lavagem, seco em estufa e autoclavado a $121^{\circ} \mathrm{C}$ por 15 minutos. Os frascos utilizados nos cultivos foram vedados com algodão, recobertos com papel para a esterilização e novamente levados à estufa para secagem completa. Após a esterilização dos frascos já preparados iniciou-se o inóculo com a Chlorella sp.

\subsection{Meio de cultura}

O crescimento da Chlorella sp é estimulado em meio suplementado, portanto para o cultivo e manutenção do inóculo, foi utilizado o meio sintético Bold's Basal Medium (BBM).

A partir das culturas mantidas em meio sólido em tubos de ensaios, foram desenvolvidas novas culturas em BBM. Os repiques das culturas algais foram feitos e após obter um volume de $500 \mathrm{~mL}$ de cultivo na fase exponencial, foi realizado um novo inóculo para cultivar utilizando a glicerina e BBM ou vinhaça e BBM, em diferentes proporções, dividindo o experimento em duas etapas.

\subsection{Resíduos líquidos como meio de cultivo}

Foi utilizada para o primeiro estudo a glicerina comercial, com o intuito de simular o resíduo líquido oriundo da reação de transesterificação para obtenção de biodiesel, já o resíduo líquido coletado para o segundo estudo, foi derivado do processo de destilação fracionada do caldo da cana-de-açúcar fermentado para a produção do etanol, os quais foram disponibilizados pela Usina São João, situada em Santa Rita - PB.

\subsection{Aclimatação dos cultivos}

A primeira etapa do experimento consistiu adicionando a glicerina no meio de cultura BBM, em uma proporção de $2 \%$. Após os resultados preliminares com o primeiro experimento, adaptou-se a microalga em um meio contendo $4 \%$ e $10 \%$ deste resíduo durante um tempo de cultivo de 3 dias.

$\mathrm{Na}$ segunda fase iniciou-se o cultivo mixotrófico com a adição da vinhaça em proporções de $10 \%, 15 \%, 20 \%$ e $25 \%$ de forma a permitir uma sólida aclimatação.

Uma vez que a microalga em estudo foi removida do seu habitat natural e submetida a uma condição de estresse (cultivo), houve a necessidade de uma aclimatação às condições em laboratório.

Por se tratar de cultivos mixotróficos, as condições físicas mantidas nas duas fases foram: temperatura de $26^{\circ} \mathrm{C} \pm 2$, agitação por meio de aeração constante realizada por injeção de ar comprimido e iluminação proveniente de lâmpadas fluorescentes de $40 \mathrm{~W}$. A condição química adotada foi a 
inoculação do cultivo no meio de cultura BBM mantendo o $\mathrm{pH}$ do meio entre 6,5 e 7,0. A figura 01 mostra as condições de aclimatação adotadas.

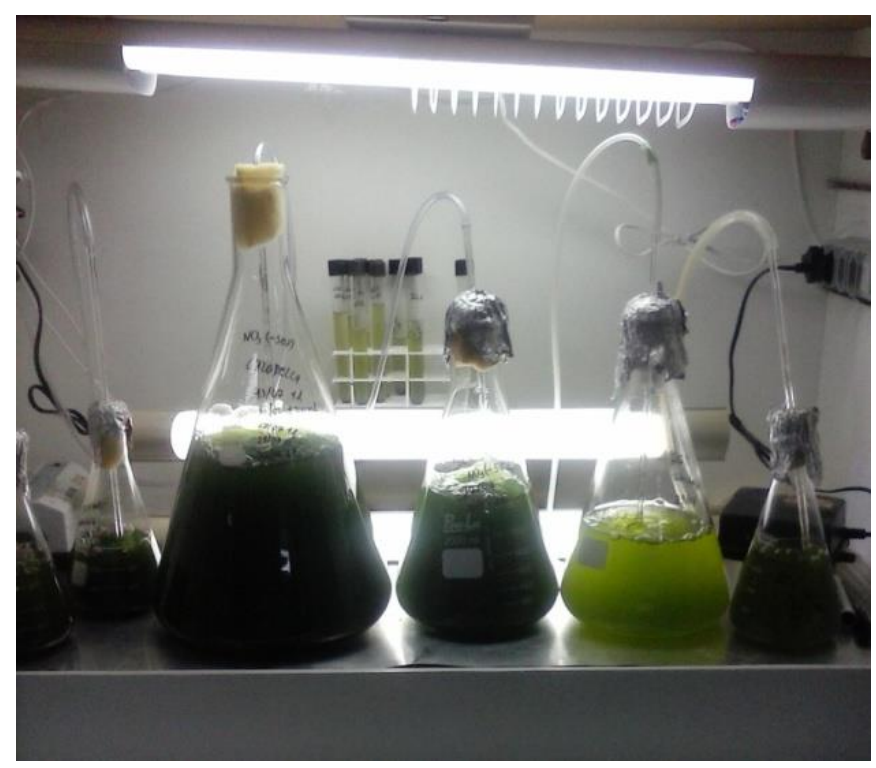

Figura 01 - Aclimatação dos cultivos

As diferentes concentrações de glicerina e vinhaça foram adotadas objetivando verificar em qual destas o crescimento algal teria melhor resultado como alternativa para um eventual tratamento e destinação destes resíduos e também como fonte de matéria orgânica para o crescimento da Chlorella $s p$ através de um cultivo mixotrófico.

\subsection{Estudos do Crescimento Celular da Chlorella sp}

O crescimento microalgal foi estimado pelo emprego de determinados parâmetros, como crescimento celular, a densidade celular e o tempo de cultivo.

\subsection{Determinação da densidade celular}

A densidade celular da biomassa cultivada em laboratório foi determinada diariamente através da microscopia óptica com aumento de 400x por contagem de células em câmara de Neubauer e expressa em número de células por mililitro de cultivo (células. $\mathrm{mL}^{-1}$ ).

Esse procedimento foi repetido após 24 horas da inoculação e, para uma melhor compreensão do crescimento da Chlorella sp, a contagem diária das células foi realizada em triplicata para cada amostra.Com isso, foram elaborados gráficos que representam as curvas de crescimento da espécie em estudo, nos quais, plotou-se no eixo da ordenada o número de células. $\mathrm{mL}^{-1}$ e no eixo da abscissa o tempo de cultivo em dia.

\subsubsection{Tempo de cultivo}

O tempo de cultivo foi definido como o número de dias passados desde o início da inoculação que corresponde ao início da fase lag, período em que as células estão se adaptando ao meio, até atingir a fase estacionária, na qual é alcançado o número máximo da densidade celular. O tempo de cultivo foi expresso em dias.

\subsection{Estudo estatístico}

O emprego de métodos estatísticos tem como objetivo alcançar soluções otimizadas dos problemas experimentais, e vem se tornando cada vez mais frequente em trabalhos envolvendo todos os tipos de materiais, principalmente os naturais. Os métodos estatísticos suavizam as dificuldades na determinação do erro experimental e a complexidade dos efeitos estudados (BOX et al., 1978). Portanto, para realização do estudo estatístico nesse trabalho, foi utilizado a versão 10 do software Statistic, a fim de validar os resultados obtidos. 


\section{RESULTADOS E DISCUSSÕES}

Este estudo centrou-se no aproveitamento de resíduos líquidos de elevado impacto ambiental, oriundos da obtenção de biocombustíveis, para o desenvolvimento da microalga Chlorella sp com potencial para produção de bioetanol e biodiesel cultivadas em fotobioreatores em escala laboratorial.

O cultivo de microalgas como a Chlorella sp tem sido associado a um grande potencial para produção de biocombustíveis. Uma das limitações para a produção de microalgas em escala industrial é a disponibilidade de suplementos nutricionais de baixo custo (CHISTI, 2007; BENEMANN, 2009). Portanto, tem-se realizado diversos estudos com o cultivo de microalgas em efluentes industriais, como uma forma de minimizar os custos de produção de biocombustíveis a partir das microalgas (BENEMANN, 2009).

Foi analisado o comportamento do crescimento da microalga por meio de dois tipos de resíduos líquidos, o primeiro estudo foi com a suplementação da glicerina comercial ao meio de cultura, a fim de simular o resíduo líquido oriundo da reação de transesterificação para obtenção de biodiesel, e o segundo estudo baseou-se no cultivo com adição da vinhaça proveniente da produção de etanol.

O crescimento das microalgas Chlorella sp foi determinado pelo incremento diário da densidade celular em função das diferentes formulações do meio de cultura modificado com adição da vinhaça em diferentes proporções. Para cada experimento foram plotados quatro curvas, pois diariamente se realizava a contagem de células em triplicada, a quarta curva corresponde às médias geométricas dos três resultados obtidos diariamente com a contagem de células para cada amostra. No estudo apresentado na Figura 02 foi realizado o cultivo sem adição de resíduos, com o intuito de verificar o desenvolvimento das microalgas o meio de cultura BBM utilizando Erlenmeyers de $1000 \mathrm{~mL}$ como fotobioreatores, mantendo as aclimatações ideais conforme descrito no procedimento experimental.

Observando o comportamento temporal do crescimento da Chlorella sp durante um cultivo com duração de 16 dias como ilustrado na Figura 02, foi verificado que o cultivo iniciou-se a fase estacionária quando atingiu a população $10^{7} \mathrm{cel} . \mathrm{mL}^{-1}$ que correspondeu a um tempo de cultivo de 8 dias, já que o número de células não apresentou elevado acréscimo a partir desse ponto, chegando ao fim do cultivo com um número máximo de células de $5,9 \times 10^{7}$ cel. $\mathrm{mL}^{-1}$.

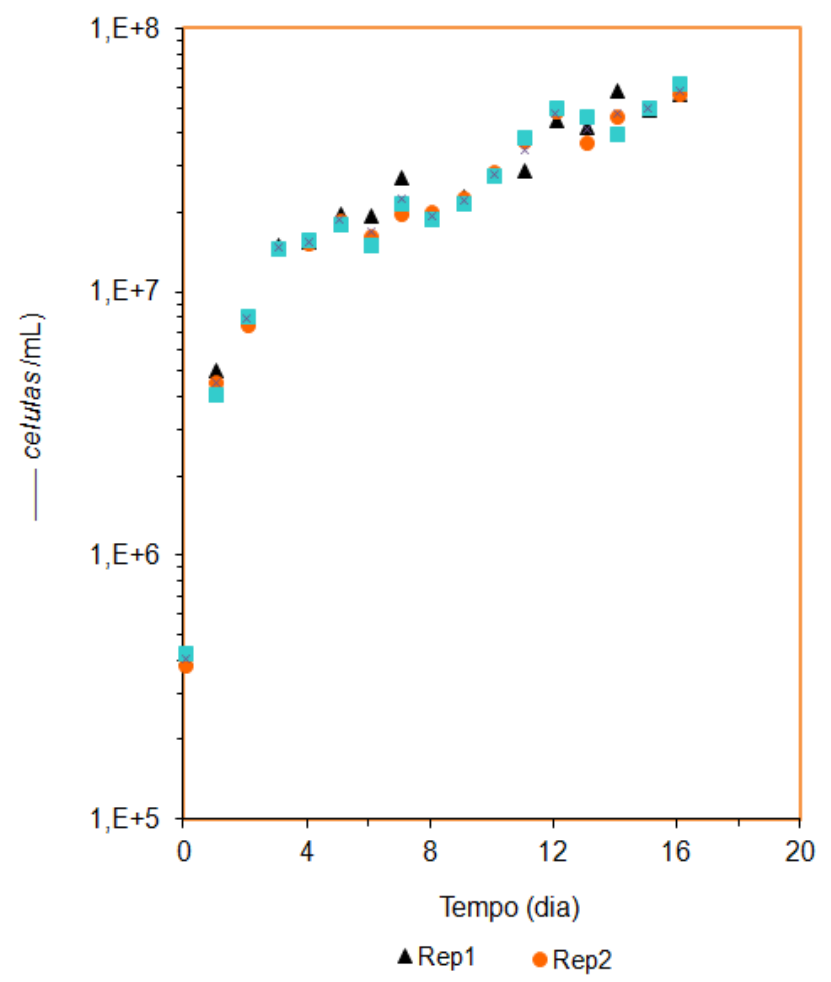

Figura 02 - Dados experimentais do Crescimento da Chlorella sp em cultivo BBM sem adição de resíduos líquidos. 
Santos et al., (2010), estudaram o crescimento da Chlorella vulgaris em meio de cultura Conway modificado com fotoperíodo de 12 horas em fotobioreatores de vidro de $250 \mathrm{~mL}$ com intensidade luminosa de 4000 lux, obtiveram a densidade máxima celular no oitavo dia cultivo de $2,5 \times 10^{7}$ cel. mL-1, analisando a Figura 02 observa-se que no oitavo dia do experimento foi obtido o número de células de 2,0 x $10^{7}$ cel. $\mathrm{mL}^{-1}$ equivalente ao obtido por Santos et al., (2010). Porém, estes autores alcançaram resultados melhores quando trabalharam com fotoperíodo integral atingindo o número máximo de células no nono dia de cultivo com um valor de $9,43 \times 10^{7}$ cel. $\mathrm{mL}^{-1}$. Valor este superior a todos os valores que foram obtidos durante o presente estudo. Porém, a justificativa para não utilizar o fotoperíodo integral neste trabalho se deve ao fato que se pretendia simular as mesmas condições ambientais do campo, uma vez que o intuito era efetuar o cultivo a céu aberto, impossibilitando assim impor um fotoperíodo integral.

Os próximos estudos mostram o crescimento do cultivo com adição de glicerina ao meio de cultura promovendo dessa forma um cultivo mixotrófico devido adição de uma fonte orgânica visando dar um destino adequado aos resíduos líquidos, bem como favorecer as reações metabólicas que favorecem o acúmulo de lipídios, pois, de acordo com os estudos de Miao e Wu (2004) que estudaram a Chlorella photothecoides e verificaram que o conteúdo de lipídios pode ultrapassar a $55 \%$ quando se realiza o cultivo heterotrófico, isso significa um aumento de 4 vezes mais que no cultivo autotrófico que atinge apenas $15 \%$ de lipídios em condições similares. Assim conclui-se que a adição de uma fonte orgânica pode não só aumentar a produção da biomassa como também o acúmulo de lipídios nas células.

Brennam e Owende (2010) compararam o cultivo autotrófico em fotobioreatores fechados com o cultivo mixotrófico, às taxas de crescimento são maiores que o cultivo em lagoas abertas. No entanto, são menores que o cultivo heterotrófico.

Chojnacka e Noworyta (2004), comparando o crescimento da Spirulina sp, em meios de cultivos autotróficos, mixotrófico e heterotróficos, encontraram que no cultivo mixotrófico reduz a foto-inibição e obtém melhores taxas de crescimento tanto com relação ao cultivo autotrófico como heterotrófico.

A Figura 03 apresenta o cultivo com adição de $2 \%$ de glicerina ao meio de cultura básico de desenvolvimento da Chlorella sp, foi observado que houve uma adaptação das células ao novo meio de cultivo, no entanto a taxa de crescimento foi relativamente baixa pois, o número máximo de células obtido foi de 2,7 x $10^{6} \mathrm{cel} . \mathrm{mL}^{-1}$, conforme pode ser verificado na Figura 03, o que mostra que a espécie em estudo não apresentou crescimento satisfatório para viabilizar a produção de biodiesel, pois, é necessário que ocorra uma alta taxa de crescimento acompanhada com o aumento do conteúdo de lipídios.

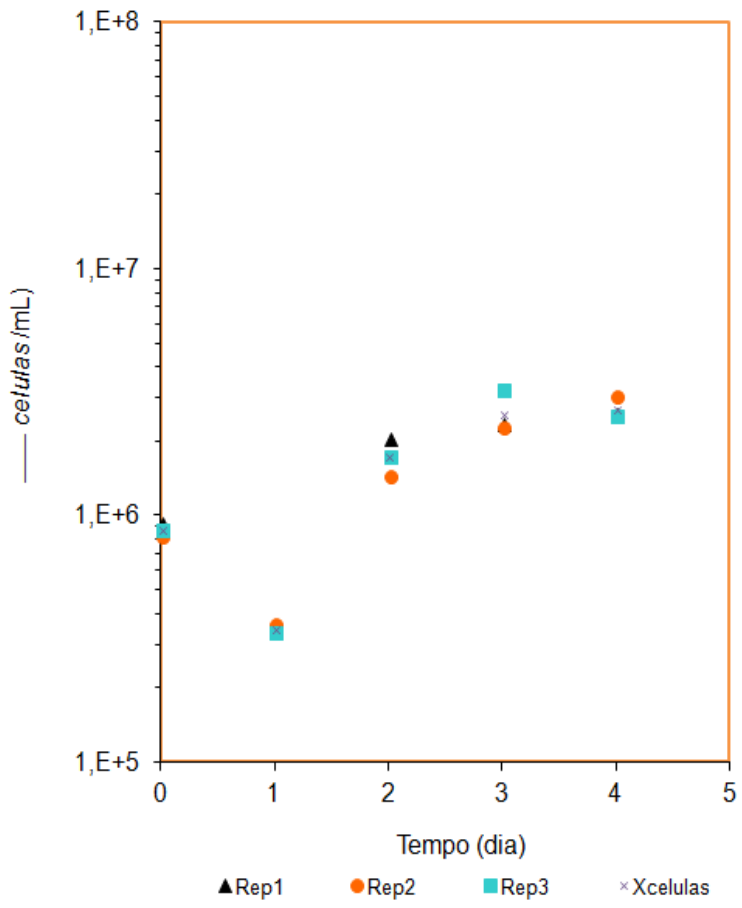

Figura 03 - Dados experimentais do Crescimento da Chlorella sp em cultivo BBM com adição 2\% de glicerina. 
A Figura 04 apresenta o cultivo da Chlorella sp com adição de 4\%, as células em estudo não apresentaram taxa de crescimento pois, houve uma fase lag de apenas um dia seguindo para a fase de declínio conforme pode ser observado na Figura 03, pois, o cultivo foi iniciado com uma concentração celular de 4,2 x $10^{6}$ cel. $\mathrm{mL}^{-1}$ finalizando com um número de células de $9,5 \times 10^{5} \mathrm{cel} . \mathrm{mL}^{-1}$, isto comprova os resultados obtidos no estudo com adição de $2 \%$ de glicerina que foi a dificuldade de crescimento da célula com adição da glicerina.

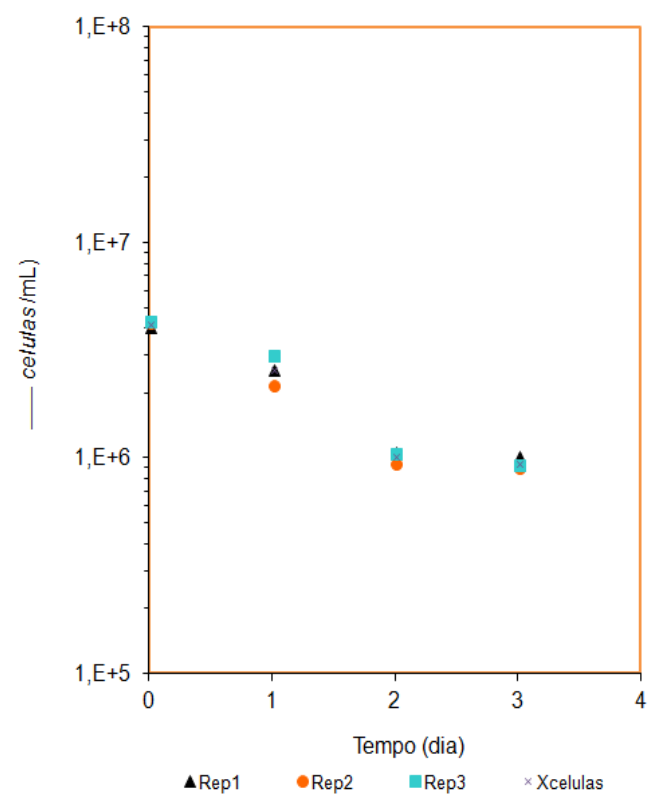

Figura 04 - Dados experimentais do Crescimento da Chlorella sp em cultivo BBM com adição 4\% de glicerina.

A Figura 05 apresenta o estudo com adição de 10\% de glicerina ao cultivo com BBM, onde foi verificado nesse estudo que as células não passaram da fase lag, não conseguindo obter crescimento desejado, o cultivo praticamente não teve incremento de células, pois, foi iniciado com o número de células de $3,1 \times 10^{6}$ cel. $\mathrm{mL}^{-1}$ e finalizou com $3,4 \times 10^{6}$ cel. $\mathrm{mL}^{-1}$.

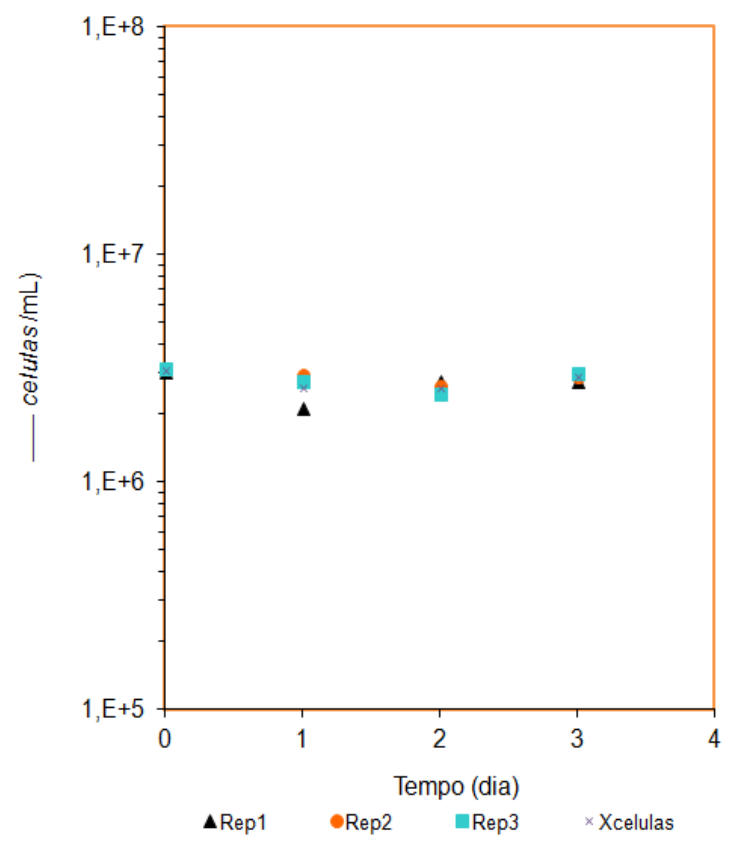

Figura 05 - Dados experimentais do Crescimento da Chlorella sp em cultivo BBM com adição 10\% de glicerina. 
Desta forma, conclui-se que o cultivo com adição de glicerina para a espécie de Chlorella em estudo não apresentou resultados satisfatórios para o desenvolvimento da célula, inviabilizando o uso do resíduo em questão para o cultivo de Chlorella sp visando a obtenção de lipídios ou outros insumos proveniente da célula em estudo.

O segundo estudo realizado foi através da adição do resíduo líquido, a vinhaça. Vale ressaltar, que o Estado da Paraíba atualmente é o terceiro produtor do Nordeste de etanol a partir da canade-açúcar, gerando dessa forma uma elevada produção de vinhaça e por ser um efluente com alto potencial poluente, seu poder poluidor é cerca de cem vezes maior que o do esgoto doméstico, devido alta concentração de matéria orgânica, possuindo uma demanda química de oxigênio de 40.000 a 70.000 mg. $\mathrm{L}^{-1}$, baixo $\mathrm{pH}$, elevada corrosividade, é considerada altamente nociva à fauna, flora, microfauna e microflora das águas doces, além de afugentar a fauna marinha que vem às costas brasileiras para procriação (FREIRE \& CORTEZ, 2000). Por estes motivos, procurou-se desenvolver as microalgas utilizando a vinhaça como suplementação ao meio de cultura.

A Figura 06 apresenta a curva de crescimento da Chlorella sp com adição de $10 \%$ de vinhaça ao meio de cultura básico, verificando uma excelente adaptação das células a nova composição do meio de cultivo, além de uma ótima taxa de crescimento, atingindo um número máximo de células de $2,57 \times 10^{7}$ cel. $\mathrm{mL}^{-1}$ em um tempo de cultivo de 5 dias, este desenvolvimento pode ser atribuído a alta concentração de nitrogênio na vinhaça.

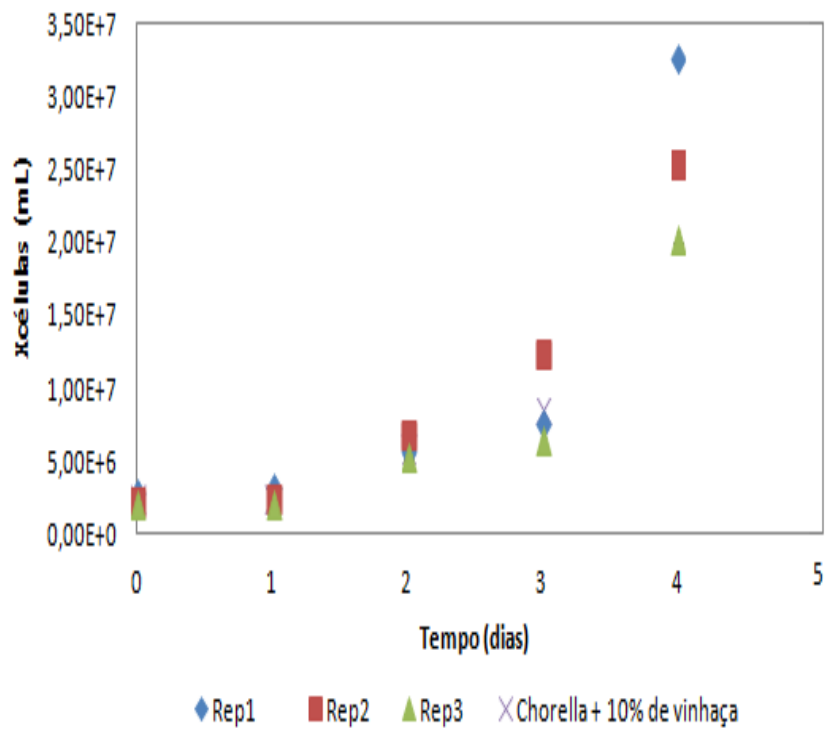

Figura 06 - Dados experimentais do Crescimento da Chlorella sp em cultivo BBM com adição 10\% de vinhaça.

De acordo com Bonini (2012) que estudou o cultivo da cianobactéria Aphanothece Microscópica Nageli e Chlorella vulgaris utilizando a vinhaça no meio de cultivo e verificou que para ambos micro-organismos ocorreu crescimento expressivo e um alto rendimento em biomassa, com destaque para a cianobactéria Aphanothece Microscópica Nageli.

Na Figura 07, para o acréscimo de $15 \%$ de vinhaça ao meio de cultura, verificou-se que a cepa em estudo não apresentou um ótimo desenvolvimento celular, pois houve um declínio do número de células após o terceiro dia de cultivo. No entanto, verifica-se que no segundo dia de cultivo obteve-se um número elevado de células atingindo $1,85 \times 10^{7} \mathrm{cel} . \mathrm{mL}^{-1}$.

$\mathrm{O}$ rápido declínio das células pode ter ocorrido devido principalmente à elevada presença de sólidos em suspensão na vinhaça que foi suplementada neste estudo, o que favoreceu a formação de grumos promovendo a aderência e sedimentação das microalgas, apesar da agitação. Além do mais, esta resposta pode estar também associada a compostos complexos de difícil assimilação pela alga, presentes na vinhaça como compostos fenólicos.

Para o estudo apresentado na Figura 08, com o acréscimo de $20 \%$ de vinhaça, tem-se uma dificuldade na adaptação celular e um crescimento lento das microalgas em estudo, com um declínio no número de células no quinto dia de contagem, obtendo um número máximo de células com 4 dias de cultivo de $6,95 \times 10^{6}$ cel. $\mathrm{mL}^{-1}$. 


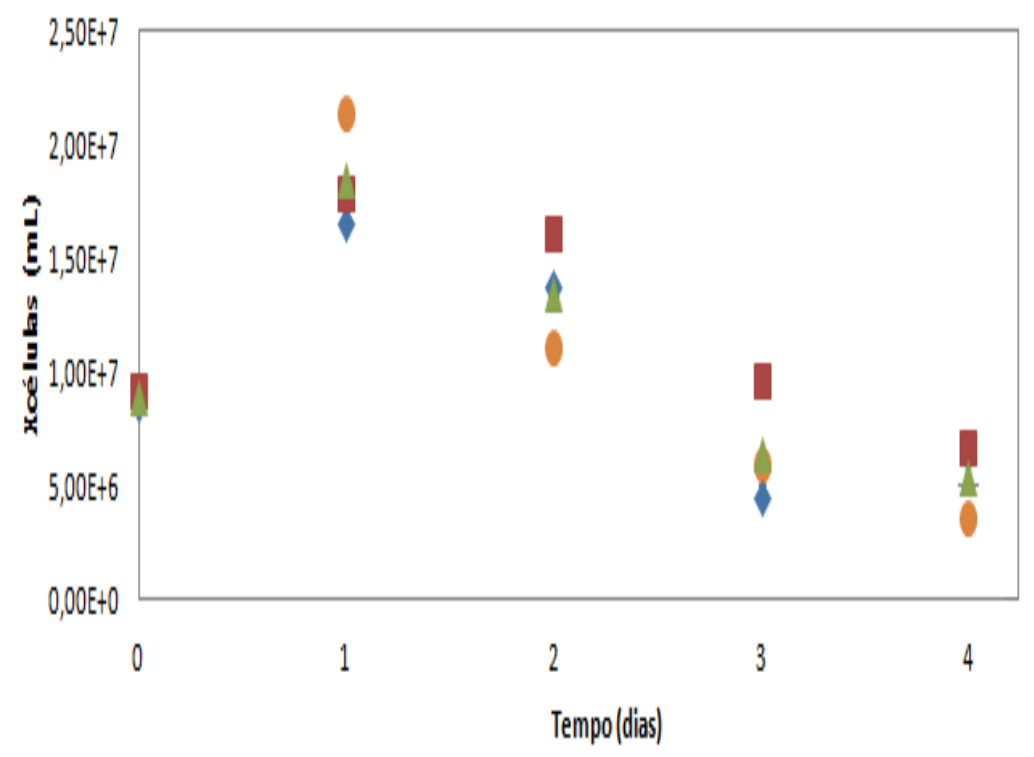

ORep1 DRep2 IRep3 IClorellat 15\% devinhaça

Figura 07 - Dados experimentais do Crescimento da Chlorella sp em cultivo BBM com adição 15\% de vinhaça.

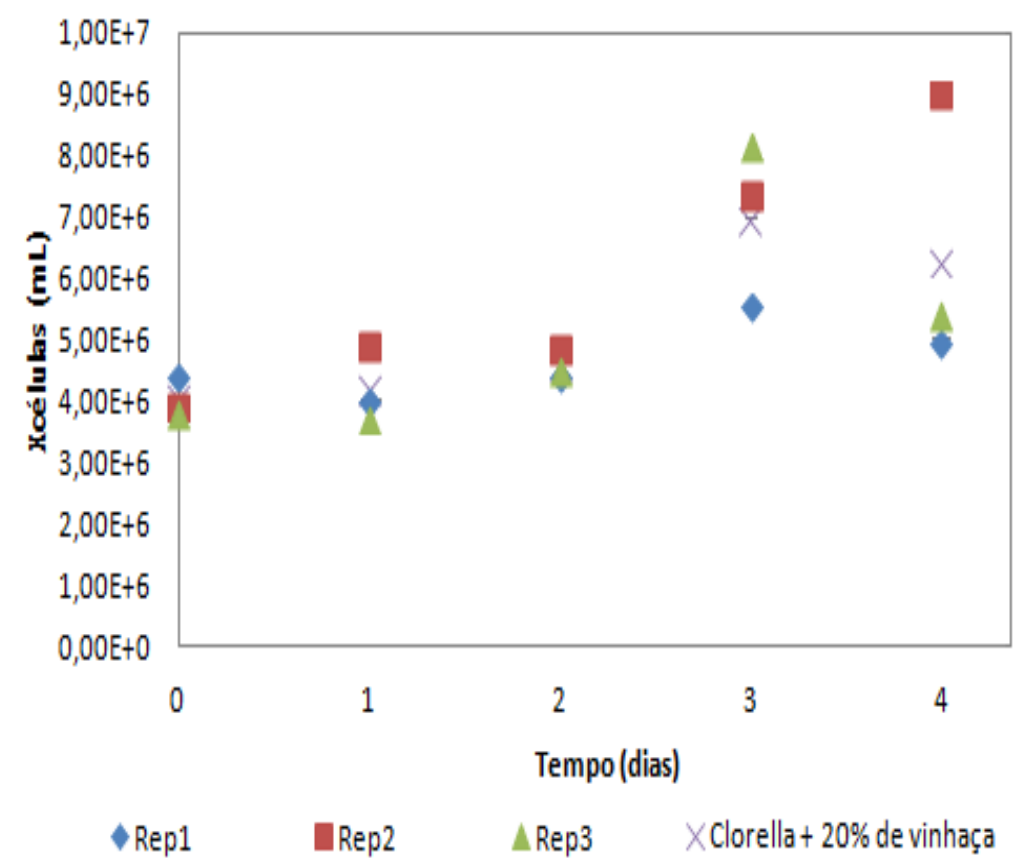

Figura 08 - Dados experimentais do Crescimento da Chlorella sp em cultivo BBM com adição 20\% de vinhaça.

A Figura 09 apresenta a curva de crescimento onde foi efetuado o cultivo com adição de $25 \%$ de vinhaça ao meio de cultura em Erlenmeyer de $1000 \mathrm{~mL}$, observa-se que o número máximo de células atingidas foi de $2,08 \times 10^{7}$ cel. $\mathrm{mL}^{-1}$ e que a partir do segundo dia de cultivo foi atingido a população de $10^{7}$ cel. $\mathrm{mL}^{-1}$, obtendo uma rápida fase $\log$, já a partir do quinto dia houve um declínio no número de células, chegando a uma população de $1,20 \times 10^{7} \mathrm{cel} . \mathrm{mL}^{-1}$.

Desta forma, conclui-se que a vinhaça apresenta características para o desenvolvimento das microalgas em estudo e que houve condições de obter o cultivo mixotrófico com a vinhaça devido à presença de sua carga orgânica e alta produção celular. No entanto, foi verificado neste estudo que a fase exponencial é obtida muito rapidamente e isto pode ser devido à presença de compostos que 
inibem o crescimento da mesma, assim sugere-se para trabalhos posteriores que seja feito um prétratamento na vinhaça, principalmente no que consiste na remoção dos sólidos em suspensão que favorecem o encrudescimento da célula, evitando que a mesma mantenha uma adequada nutrição, pois as substâncias em suspensão evitam que as microalgas mantenham o contato com os nutrientes, impedindo o desenvolvimento do cultivo.

Efetuando uma relação entre a utilização de meio de cultura suplementado com uma fonte orgânica como o glicerol e o uso de águas residuais, verificou-se que os resultados obtidos com vinhaça, indicam que ocorrem um maior crescimento juntamente com um consumo mais satisfatório da fonte de carbono por microalgas em meios mais complexos, como os resíduos líquidos industriais, que quando se utilizam meios de cultivo padrão suplementado com uma fonte de carbono. Isto pode ser atribuído, provavelmente, a presença de outros nutrientes essenciais e da relação carbono-nitrogênio das águas residuais, que contribuíram satisfatoriamente para o crescimento da biomassa.

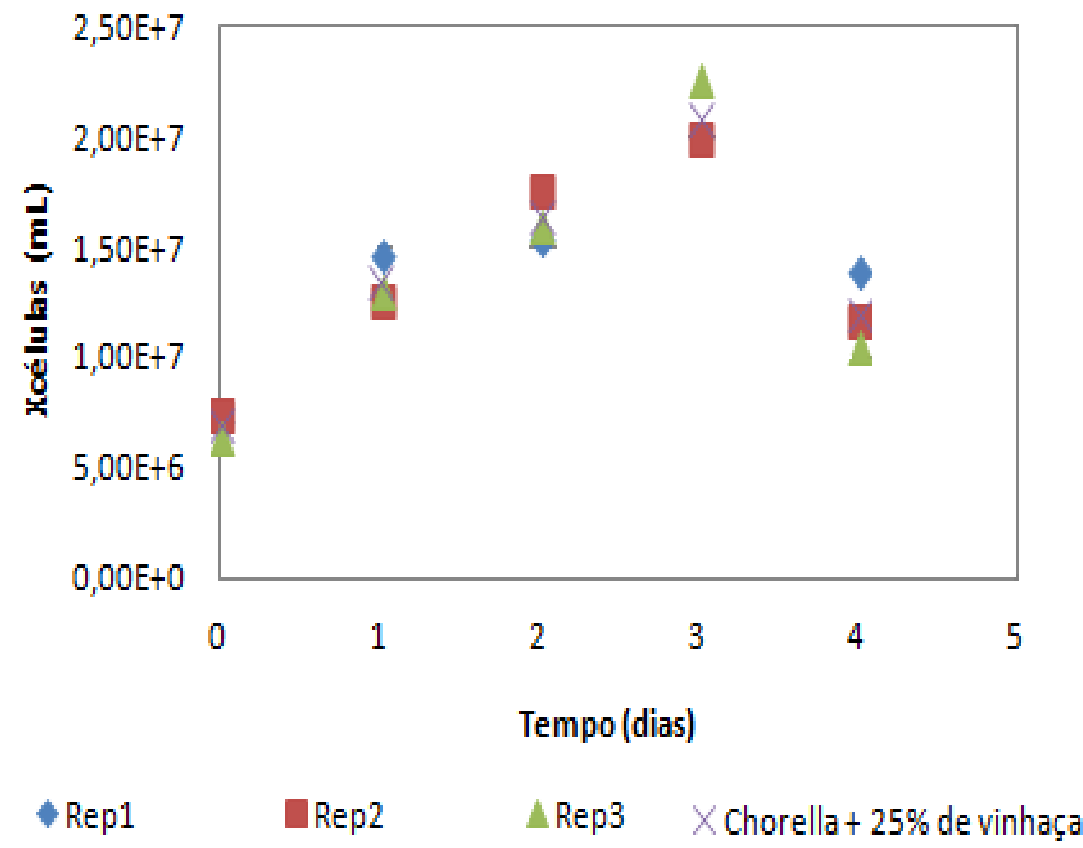

Figura 09 - Dados experimentais do Crescimento da Chlorella sp em cultivo BBM com adição 25\% de vinhaça.

\subsection{Estudo estatístico dos resultados}

Analisando o cultivo mixotrófico com a glicerina, pode ser observado através do diagrama de Pareto, mostrado na Figura 10, que a interação entre a concentração de glicerina e tempo foi significativa estatisticamente de acordo com o valor de $\mathrm{p}=0,000063$ para o cultivo e contribuíram positivamente para a maior concentração de biomassa. Representando assim que, para obter a máxima concentração de células é preciso ter maior teor de glicerina com maior tempo de cultivo, o que pode ser confirmado nos resultados experimentais, pois a maior concentração de biomassa foi com a glicerina a $10 \%$ ao final do terceiro dia e por outro lado a menor concentração de biomassa máxima foi verificada no primeiro dia do cultivo com $2 \%$ de glicerina, pode-se afirmar que os resultados obtidos foram significativos estatisticamente. $\mathrm{O}$ modelo reduzido e codificado proposto para analisar a máxima concentração de biomassa em função dos parâmetros tempo e concentração de glicerina esta apresentado na equação 1.0, mostrando que a interação do tempo com a glicerina causa um efeito contrário ao crescimento, isso acontece porque a medida de o microrganismo cresce há o consumo dos nutrientes.

$$
z=-1,68+1,41 x+0,44 y-0,13 x y
$$

\section{(Equação 1.0)}


Onde:

$\mathrm{x}$ - tempo

y - concentração de glicerina

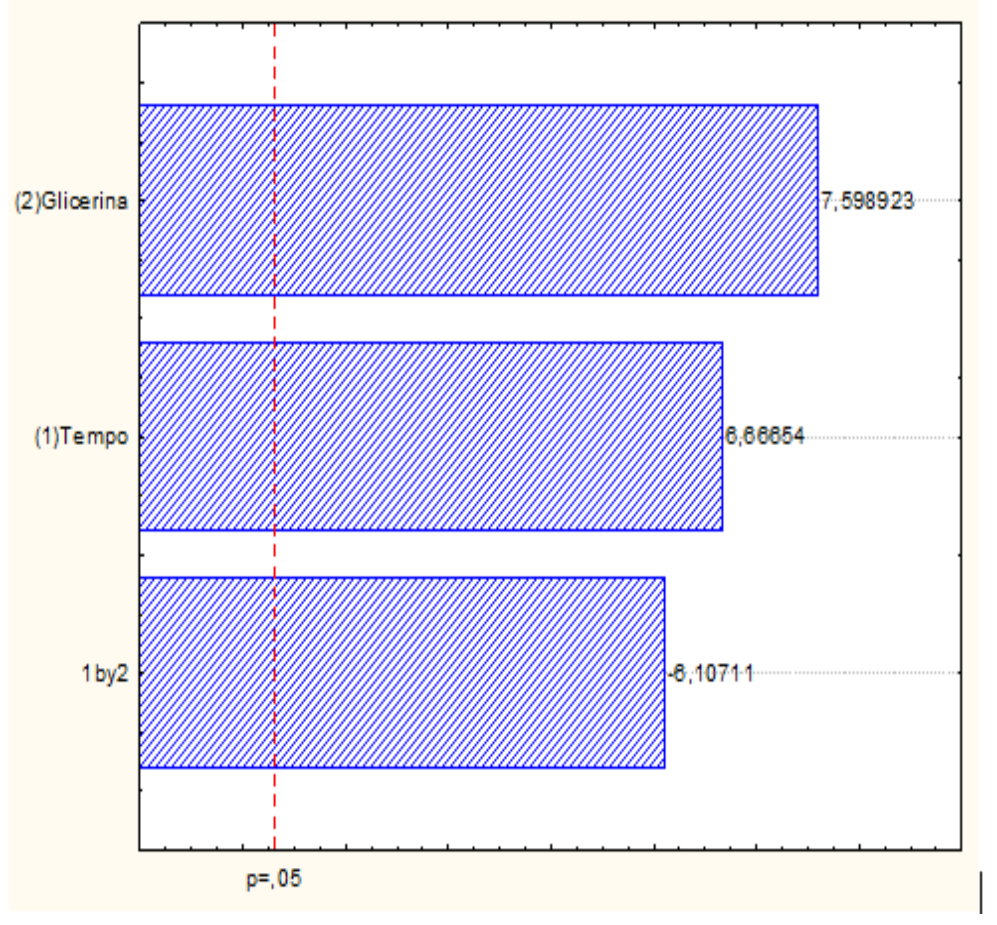

Figura 10 - Diagrama de Pareto da máxima concentração de biomassa no experimento utilizando a glicerina.

A superfície resposta, mostrada na Figura 11, baseada no modelo proposto pela Equação 1.0 permite uma melhor visualização dos efeitos que as variáveis estudadas exercem na máxima concentração de biomassa da microalga Chlorella sp. Os termos da equação representam a concentração da biomassa, no eixo $\mathrm{z}$, o tempo em x, e a concentração de glicerina no eixo y.

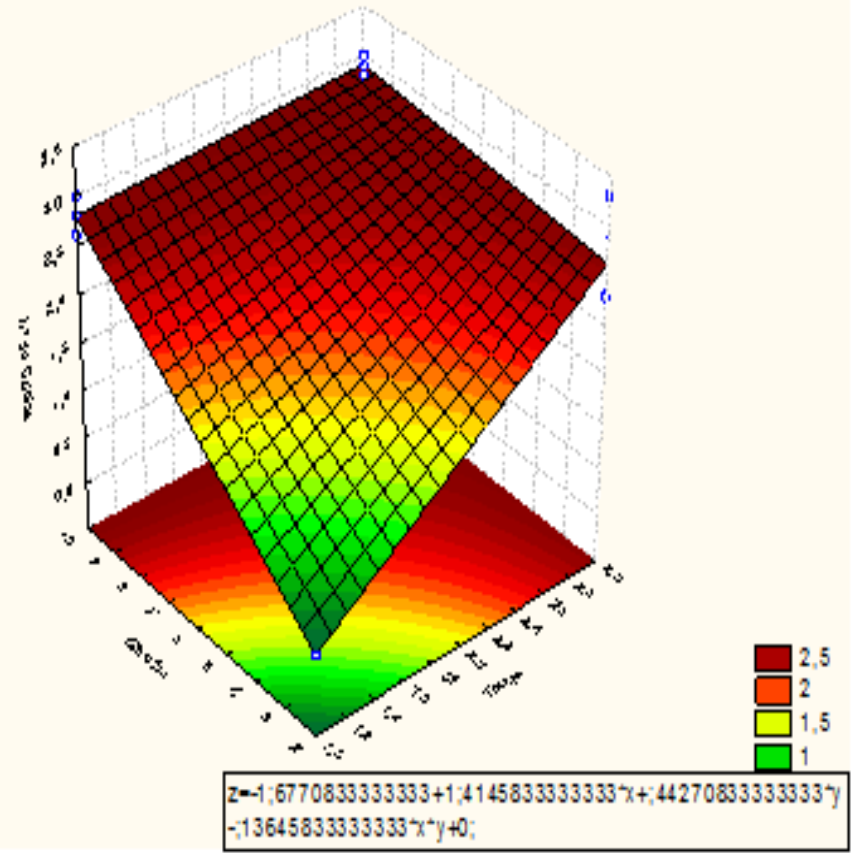

Figura 11 - Superfície de resposta para o modelo de concentração de biomassa utilizando a glicerina. Os pontos brancos representam os valores experimentais. 
O estudo estatístico avaliado com a suplementação de vinhaça ao meio de cultura pode ser observado através do diagrama de Pareto, apresentado na Figura 12 verificando que o estudo com uso de vinhaça é estatisticamente significativo e contribui positivamente para o aumento da concentração de biomassa. No entanto, o tempo nesse estudo não foi estatisticamente significativo para o valor $p$ $=0,005517$ o que demonstra uma baixa relação de dependência do aumento de biomassa em função dessa variável. O modelo reduzido e codificado proposto para a máxima concentração de biomassa é dado pela Equação 1.1.

$$
z=46,76-20,40 x-1,48 y+0,96 x y
$$

Onde:

\section{(Equação 1.1)}

$\mathrm{x}$ - tempo

y- concentração de vinhaça

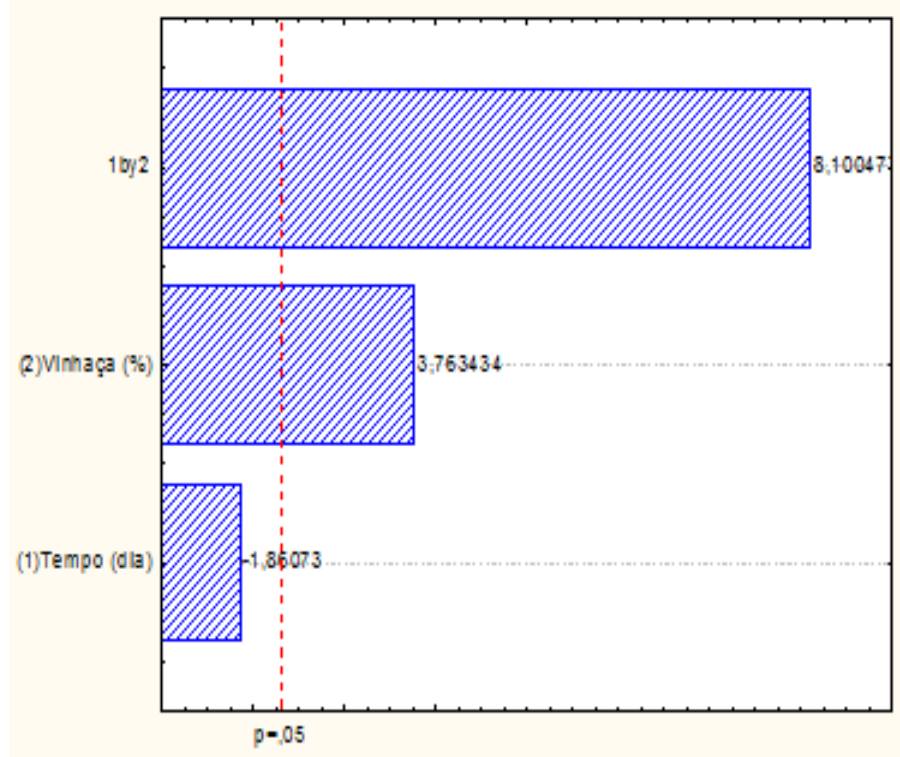

Figura 12 - Diagrama de Pareto da máxima concentração de biomassa no experimento utilizando a vinhaça como fonte orgânica.

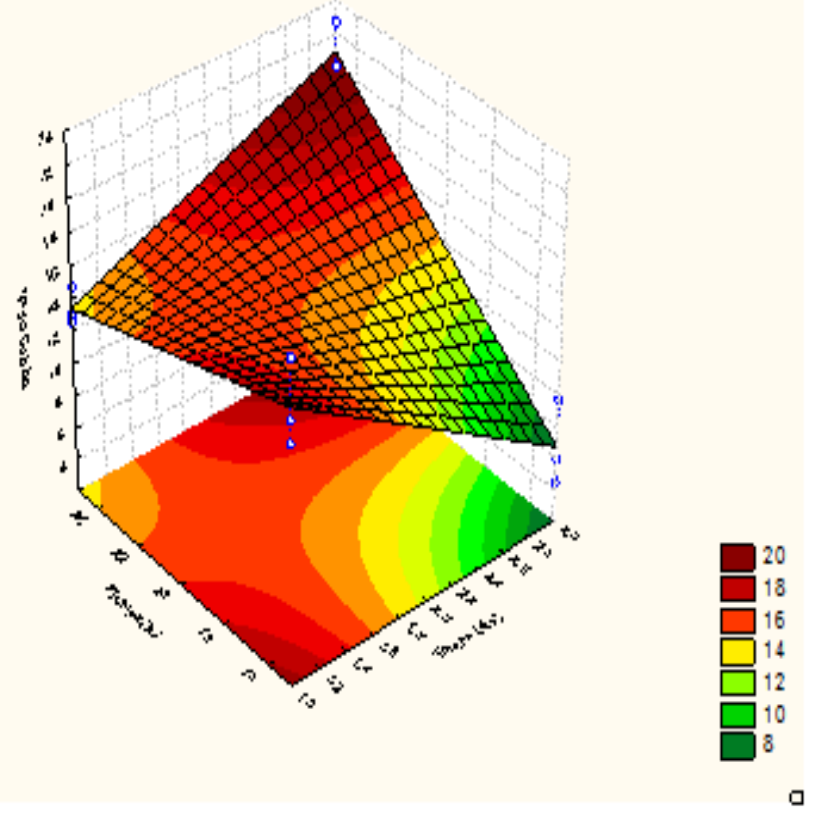

Figura 13 - Superfície de resposta para o modelo de concentração de biomassa no experimento utilizando a vinhaça. Os pontos brancos representam os valores experimentais. 
A superfície resposta apresentada na Figura 13 baseada no modelo proposto pela Equação 1.1 permite uma melhor visualização dos efeitos que as variáveis estudas exercem na máxima concentração de biomassa de Chlorella sp.

\section{CONCLUSÕES}

Através dos resultados obtidos durante o estudo, pôde-se constatar que a microalga Chlorella $s p$ apresenta um ótimo crescimento celular quando utiliza-se o efluente da indústria sucroalcooleira (vinhaça) como fonte de nutriente. Trata-se, portanto, de uma técnica viável, pois dará um destino adequado para esse resíduo líquido gerado no processo de obtenção do etanol.

A proporção de vinhaça que obteve melhor crescimento foi com a suplementação de $10 \%$, onde se verificou uma excelente adaptação das células a nova composição do meio de cultivo. Verificou-se também que o excesso de material em suspensão presente na vinhaça pode ter prejudicado no crescimento celular quando utilizou proporções maiores de $10 \%$ ao meio de cultivo, ressaltando assim a importância de efetuar um pré-tratamento da vinhaça, para que não dificulte o crescimento das células ao ser adicionado o resíduo líquido como meio de cultura. Com o uso da vinhaça obteve-se elevadas taxas de crescimento que corrobora para a produção de biodiesel, pois, para a viabilidade de geração de biocombustíveis, deve-se ter associado a altas taxas de crescimento acompanhadas com concentrações elevadas de lipídios ou carboidratos.

Desta forma, conclui-se que o desenvolvimento em cultivo mixotrófico das microalgas através da suplementação do meio de cultura com os resíduos oriundos das indústrias sucroalcooleiras torna-se viável, podendo com isso favorecer a produção de outra fonte energia renovável, incrementando assim o potencial de geração de energia nas próprias usinas de etanol. O cultivo mixotrófico por meio da adição de glicerina como meio de cultura da Chlorella sp não apresentou crescimento favorável mesmo em baixas proporções inviabilizando o desenvolvimento celular e consequentemente a produção de biodiesel a partir das microalgas.

\section{REFERÊNCIAS}

BENEMANN, J.R. Microalgal Biofuels: A Brief Introduction. Benemann Associates. 2009.

BONINI, M.A. Cultivo heterotrófico de Aphanothece microscópica Nageli e Chlorella vulgaris em diferentes fontes de carbono e vinhaça. 2012. 96f. Dissertação (Mestrado em Agricultura e Ambiente), Universidade Federal de São Carlos, São Carlos, 2012.

BOROWITZKA, M.A. Products from microalgae. Infofish International, v.5, p. 21-26, 1993.

BOX, G. E. P.; HUNTER, J. H.; HUNTER, W. G. Statistics for Experimenters : An Introdution to Desing, Data Analysis and Model Bilding. New York: John Wiley \& Sons, 1978, 653p.

BRENNAM, L.; OWENDE, P. Biofuels from microalgae - A review of Technologies for production, processing, and extractions of biofuels and co-products. Renewable and Sustainable Energy Reviwes, v. 14, p. 557-577, 2010.

CHISTI, Y. Biodiesel from microalgae beats bioethanol. Trends in Biotechnol, v.26, n. 3, p. 126-131, 2007.

CHOJNACKA, K.; NOWORYTA, A. Evaluation of Spirulina sp. Growth in photoautotrophic, heterotrophic and mixotrophic cultures. Enzymeand Microbial Technology, v.5, p. 34- 46, 2004.

DICKINSON K.E., WHITNEY C.G., MCGINN P.J. Nutrient remediation rates in municipal wastewater and their effect on biochemical composition of the microalga Scenedesmus sp. AMDD. Algal Research, 2013. 
EMBRAPA- Empresa Brasileira de Pesquisa Agropecuária. Plano Nacional de Agroenergia. 2. ed. rev. Brasília, DF: Embrapa Informação Tecnológica, 110p., 2006.

FERREIRA,W.B. Aproveitamento do concentrado da dessalinização via osmose Inversa para desenvolvimento de Chlorella sp e Chlorella vulgaris visando a Produção de biodiesel. Tese (Doutorado em Engenharia Química), Universidade Federal de Campina Grande, Campina Grande - PB, 2012.

FREIRE, W. J.; CORTEZ, L. A. B. Vinhaça de cana-de-açúcar. Guaíba: Agropecuária, 203p., 2000.

MALCATA, X.F.; GUEDES, A.C.; AMARO, H.M. Advances and perspectives in using microalgae to produce biodiesel. Applied Energy, v. 88, p. 3402-3410, 2011.

MIAO, X.; WU, QY. High yield bio-oil production from fast pyrolysis by metabolic controlling of Chlorella protothecoides. Journal of Biotechnology, v.110, p.85-93, 2004.

MIRANDA, J.R.P.C. Produção de bioetanol a partir da Microalga Scenedesmus obliquus. 2011. 102f. Dissertação (Mestrado em Energia e Bioenergia), Universidade Nova de Lisboa, Lisboa, 2011.

ORPEZ R., MARTÍNEZ M.E., HODAIFA G., YOUSFI F.E., JBARI N., SÁNCHEZ S. Growth of the microalga Botrycoccus braunii in secondarily treated sewage. Desalination, 2009.

PAIXÃO, M. C. S.; FONSECA, M. B. A produção de etanol de cana no Estado da Paraíba: alternativas de Sustentabilidade. Revista Desenvolvimento e Meio Ambiente. Paraná: Ed. UFPR, n. 24, p. 171-184, 2011.

PHUKAN, M.M.; CHUTIA, S.R.; KONWAR, K.B.; KATAKI, R. Microalgae Chlorella as a potential bio-energy feedstock. Applied Energy, 2011.

PRADO, T. G. F. Externalidades no ciclo produtivo da cana-de-açúcar com ênfase na geração de energia elétrica. 2007. 254p. Dissertação (Mestrado - Programa Interunidades de Pós-Graduação em Energia), Universidade de São Paulo, São Paulo, 2007.

SANTOS, L.B.G.; CALAZANS, N.K.F.; MARINHO, Y.F.; SANTOS, A.P.F.; NASCIMENTO, R.DM.; VASCONCELOS, R.F.L.; MACÊDO, D.M.; GALVEZ, A.O. Influência do fotoperíodo no crescimento da Chlorella vulgaris (Chlorophyceae) visando produção de biodiesel. p.3, 2010.

TUANTET K., JANSSEN M., TEMMINK H., ZEEMAN G., WIJFFELS R.H., BUISMAN C.J.N. Microalgae growth on concentrated human urine. J Appl Phycol, 2013.

VAN H.V., THI H.M.N. Bioethanol production from marine algae biomass: prospect and troubles. Journal of Vietnamese environment, v.3, p.25-29, 2012. 